\title{
Mouse gene repository plans likely to persuade Italy to stay in EMBL
}

Munich. Italy is almost certain to withdraw its notice to quit the European Molecular Biology Laboratory (EMBL), following last week's approval by the EMBL council of a plan for a European-level mouse gene repository and research facility near Rome.

The plan would include an application to the European Commission in Brussels for joint funding for the repository. The Italian government, which had planned to leave EMBL at the end of this year, is now expected to decide within the next few weeks to remain a member.

Last December, Italy gave 12 months notice to leave EMBL, claiming that it was not getting value for money on its subscription. It pointed out, for example, that although it pays DM10 million (US\$6.4 million) to EMBL, 16 per cent of the EMBL budget, there are relatively few Italian staff at the main laboratory in Heidelberg (see Nature 366, 604; 1993).

Fotis Kafatos, the new director-general of the laboratory, put forward two proposals in February for increasing the value of EMBL to southern European countries. One was to recruit more staff from such regions, the second to set up EMBL regional research groups at host institutes in southern Europe.

The measures were welcomed by many Italian biologists. But the Italian government felt they were insufficient, and wanted EMBL to establish an outstation in Italy along the lines of those in Germany (at the DESY accelerator in Hamburg), France (at the Institut Laue-Langevin in Grenoble) and the United Kingdom (the European Bioinformatics Institute, which is situated near Cambridge).

After reassurances at its meeting last week that Italy would be unlikely to leave the organization if a compromise could be reached, the EMBL council voted unanimously for a scheme that combines elements of both proposals. This would involve supporting a bid from several national research organizations to create a Europeanlevel repository for mouse genes and establishing four EMBL research groups at laboratories donated by the Italian chemical company Enichem at Montorotondo, near Rome (see Nature 369, 699; 1994).

The research groups at the centre would replace the four EMBL regional groups that were planned to be spread throughout Italy. The Consiglio Nazionale della Ricerche (CNR), Italy's basic research organization, will also establish research groups to work alongside the EMBL scientists.

The proposal to establish a repository for mouse genes at the site is being put forward by the major research organizations in the four countries in which EMBL has laboratories. Earlier this month, these four research organizations, Germany's Max Planck Society, the UK's Medical Research Council (MRC), Italy's CNR and France's Centre National de la Recherche Scientifique, set up a committee of scientists to assess the suitability of the Montorotondo facilities for this purpose.

Peter Gruss from the Max Planck Institute for Biophysical Chemistry in Göttingen, who co-chairs this committee with Peter Rigby from the MRC's National Institute for Medical Research, says that if the com-

\section{Faraday successor targets the brain}

London. Susan Greenfield (right), a lecturer in pharmacology at the University of Oxford, will become the first woman to present the Royal Institution (RI) Christmas Lectures later this year when she gives five lectures for children from the age of 10 upwards on the workings of the brain.

Among the subjects to be covered in the 165th series of the lectures, started by Michael Faraday in 1826 and now broadcast annually by the BBC, are methods for studying the brain, how it receives signals about its environment and converts these into electrical Impulses and chemical transmitters, the brain's development, memories and intelligence, and what makes a human being unique.

Greenfield is seen with a statue of Faraday, one of the RI's most prominent scientific members - and a hero of the former prime minister, Lady (Margaret) Thatcher. mittee approves the site - there are no other candidates at present - the consortium of research organizations will submit a formal proposal to the commission for funds for genetic repositories in Europe available under the Framework IV programme. The commission expects to put out a call for proposals in the next few weeks.

They will not know if they have been successful until at least next spring. But Gruss is optimistic of its chances, as the idea has been discussed extensively within the commission's research directorate, and has the active support of Antonio Ruberti, the research commissioner. Gruss adds that he sees no reason to suppose that Ruberti's successor, Edith Cresson, would be less supportive.

Kafatos says that he will be "willing to assist in any way to get [the proposal] approved", but stresses that it is independent of EMBL, and not directly part of the deal to draw Italy back into the EMBL fold.

If all goes according to plan, work could start at Montorotondo by the end of next year.

Alison Abbott

\section{Balzan prize shared by astrophysicists and neurobiologist}

Rome. Two astrophysicists, Sir Fred Hoyle and Martin Schwarzschild, and the French neurobiologist René Couteaux, are this year's recipients of the Balzan prize for lifelong contributions to science. The prize, worth SFr350,000 (US\$266,000) to each recipient, is awarded to natural and social scientists in areas not covered by the Nobel prize.

Hoyle, who is 79, and Schwarzschild, 82,

兽 were recognized for their work on stellar evolution. Hoyle demonstrated that carbon and heavier elements can be produced by nuclear reactions in stars. He also predicted - correctly - that the carbon nucleus could exist in an excited state with just the right energy to allow its formation from three helium nuclei.

Working with the German-born Schwarzschild, Hoyle developed the theory that low-mass stars can evolve into very luminous giants, an important stage in understanding the physical processes of stellar evolution. Schwarzschild, who has spent most of his career in the United States, also pioneered the use of telescopes carried by balloons for taking images of the Sun, planets and stellar systems.

Couteaux, who is 85 , described during his half-century of active research the detailed structure of the neuromuscular junction. A. A. 